\title{
ARRANJOS ORGANIZACIONAIS DE BIOTÉRIOS EM UNIVERSIDADES PÚBLICAS BRASILEIRAS
}

LABORATORY ANIMAL FACILITIES' ORGANIZATIONAL ARRANGEMENTS IN BRAZILIAN PUBLIC UNIVERSITIES

\author{
FÁBIO TONISSI MORONI ${ }^{1}$ \\ EDUARDO LOEBEL ${ }^{2}$
}

\begin{abstract}
Resumo: Os biotérios são instalações que oferecem serviços de apoio para a reprodução, manutenção e experimentos com animais de laboratórios na pesquisa biomédica em diferentes organizações, incluindo as universidades públicas brasileiras. A recente demanda por alinhamento das práticas administrativas com os procedimentos definidos pela legislação brasileira requer formas organizacionais e modelos de gestão éticos e eficazes. 0 objetivo geral deste artigo é colocar em debate a questão dos arranjos organizacionais de biotérios em universidades públicas brasileiras. Os objetivos específicos são: 1) desenvolver uma equivalência categórica da tipologia proposta por CGEE (2003) com os arranjos organizacionais propostos por Mintzberg (2012); 2) constatar, por meio de um levantamento empírico, uma representação dos arranjos organizacionais típicos na realidade brasileira; 3 ) discutir as bases de um modelo de desenvolvimento organizacional, as possibilidades e limitações dos arranjos organizacionais típicos estudados. O presente trabalho empregou o método tipológico, conforme Marconi e Lakatos (2005). Como resultado, discute-se as bases de um modelo de desenvolvimento organizacional e apresenta-se um mapeamento das possibilidades e limitações de arranjos organizacionais típicos em relação aos processos de pesquisa translacional. A conclusão é que três formas organizacionais ideais estruturam os biotérios em universidades públicas brasileiras. Propomos uma trajetória de desenvolvimento organizacional por meio da interconexão de tipos de ideias ao longo do tempo. Cada tipo ideal, na prática, carrega um conjunto de possibilidades e limitações. 0 processo de gestão deveria considera-las. As contribuições são o avanço das questões sobre os arranjos organizacionais de biotérios aos públicos acadêmico e prático no campo de pesquisa translacional.
\end{abstract}

Palavras-chave: biotério; universidade pública brasileira; arranjo organizacional; gestão de biotérios.

ABSTRACT: Laboratory animal facilities are installations that offer services for reproduction, maintenance and experiments with laboratory animals in biomedical research in different organizations, including Brazilian public universities. The recent demand for alignment of administrative practices with the procedures defined by Brazilian legislation requires ethical and effective organizational forms and management models. The general objective of this article is to put into question the problem of the laboratory animal facilities' organizational

Data de submissão: 06/03/2017 Data de aceite: 25/02/2018 Data de publicação:

${ }^{1}$ Doutorado em Biologia de Água Doce e Pesca Interior pelo Instituto Nacional de Pesquisas da Amazônia (2005). Atualmente é professor adjunto nível 4 da Universidade Federal do Amazonas (UFAM). Universidade Federal de Uberlândia

${ }^{2}$ Doutor em Ciências Sociais (Sociologia) pela PUC-SP (2006). Universidade Federal de Uberlândia. 
arrangements in Brazilian public universities. The specific objectives are: 1) to develop a categorical equivalence of the typology proposed by CGEE (2003) with the organizational arrangements proposed by Mintzberg (2012). 2) To verify, through an empirical survey, a representation of the typical organizational arrangements in the Brazilian reality. 3) To discuss the bases of an organizational development model, the possibilities and limitations of the typical organizational arrangements studied. The present work used the typological method, according to Marconi and Lakatos (2005). As a result, we discuss the bases of an organizational development model and present a mapping of the possibilities and limitations of typical organizational arrangements in relation to the translational research process. The conclusion is that three ideal organizational forms structure the Laboratory animal facilities in Brazilian public universities. We propose an organizational development trajectory through the interconnection of ideas types over time. Each ideal type, in practice, carries a set of possibilities and limitations. The management process should consider them. The contributions are the advancement of questions about the organizational arrangements of laboratory animal facilities to academic and practical audiences in the field of translational research.

Keywords: laboratory animal facility; Brazilian public university; organizational arrangement; laboratory animal facilities management;

\section{INTRODUÇÃO}

Grande parte do conhecimento científico produzido pelas ciências biomédicas, biológicas e biotecnológicas é fundamentada em resultados obtidos na pesquisa que utiliza modelos animais, convencionalmente denominados "animais de laboratório" (PRESGRAVE, 2002, p. 361). Tal prática ainda é uma necessidade para a maioria dos protocolos de ensino e pesquisa no campo, pois são poucos os métodos alternativos validados (CERQUEIRA, 2008; RIVERA, 2010).

Os biotérios são instalações nas quais são prestados serviços de reprodução, manutenção e experimentos para animais de laboratórios, por exemplo, ratos e camundongos, utilizados como modelos animais em várias pesquisas experimentais, tais como: pesquisa e desenvolvimento de novos fármacos, ensaios toxicológicos, controle de qualidade de medicamento e imunobiológicos, pesquisa e desenvolvimento de novas técnicas cirúrgicas, estudo do mecanismo de desenvolvimento de doenças genéticas, entre outras finalidades, que se fundamentam e utilizam modelos animais para mimetizar realidades que sejam extrapoláveis aos humanos, sendo tecnicamente denominado como experimentação animal (BRAGA, 2010; LAUZ et al., 2008; MASSIRONI, 2010; MUSCHLER et al., 2010; QUEVEDO et al., 2008). A experimentação animal é regulamentada pela Resolução Normativa RN no 3, de 14 de dezembro de 2011 promulgada pelo Conselho Nacional de Controle de Experimentação Animal (CONCEA) do Ministério da Ciência, Tecnologia e Inovação brasileiro.

Um aspecto importante para a gestão de instalações de animais de laboratório é o uso ético de animais em ensino e pesquisa, com o objetivo de reduzir, refinar e substituir os animais de laboratório (FESTING et al., 1998; RUSSELL; BURCH, 1959/1992). Seguindo esse princípio básico, leis nacionais são criadas para inibir atitudes abusivas que geram dor e angústia aos animais (BRUNE, 2002; GOLDBERG, 2002; ROLLIN, 2007, 2011; VAN ZUTPHEN, 
2002). No Brasil, o instrumento jurídico criado para estabelecer procedimentos para o uso científico de animais é a Lei 11.794 de outubro de 2008, regulamento pelo Decreto 8.699 de novembro de 2010, que regula o item VII, § 1일 do artigo 225 da Constituição Federal Brasileira. Esta legislação estabelece normas e procedimentos para o uso científico e didático dos animais de laboratório. Logo, uma mudança ambiental que requer adaptação dos biotérios brasileiros encontra-se em pleno curso provocando demandas por alinhamento das práticas administrativas com os procedimentos definidos pela legislação brasileira. Pressupomos nesse trabalho que tais demandas por alinhamento ao ambiente externo inclui questões relacionadas com as formas organizacionais e os modelos de gestão éticos e eficazes de biotérios brasileiros, em particular aqueles que operam dentro de universidades públicas.

Por serem organizações especialmente sensíveis em sua dimensão éticas, os biotérios buscam atingir os propósitos organizacionais associados à busca do bem comum. Esse é definido como o conjunto de condições sociais que permite e favorece aos membros da sociedade o seu desenvolvimento pessoal e integral (ALONSO; LÓPEZ; CASTRUCCI, 2012). O bem comum, em cada sociedade, compromete a todos os seus membros, especialmente as autoridades e os corpos diretivos. Concretamente, não basta que os biotérios alojem animais. É necessário desenvolver a cultura do respeito ao bem-estar dos homens e animais, e a consciência de se posicionar eticamente diante de certos assuntos polêmicos que fazem parte do cotidiano dos biotérios. Segundo Macrina (2007), o bem-estar animal é um assunto relacionado à ética na pesquisa científica tão importante quando outros aspectos éticos na atividade científica, relacionados à proteção dos serem humanos. Para tanto, o bioterista deve adquirir uma forte compreensão dos métodos utilizados da pesquisa biomédica e os fatores que comprometem a integridade científica dos trabalhos realizados, a fim de contribuir de forma efetiva com a geração de conhecimentos das pesquisas translacionais, cujos dados obtidos serão aplicados na medicina humana.

No entanto, além da institucionalização do uso ético dos animais para o ensino e a pesquisa, para que a gestão seja eficaz é necessária também a escolha de um arranjo organizacional adequado. Nos últimos anos, a necessidade de alinhamento dos procedimentos operacionais, o status sanitário dos animais alojados e o nível de infecção dos animais por agentes patogênicos aumentaram a exigência dos usuários das instalações e, consequentemente, a sua complexidade administrativa (DEMERS et al., 2006). As modernas instalações de animais de laboratório buscam atender além da legislação local normas operacionais, internacionalmente aceitas pela comunidade científica para acreditação, visando garantir a possibilidade de discussão e comparação dos dados obtidos com a literatura científica internacional (BAYNE, 2008; BAYNE; MILLER, 2000; KATOH, 2000; NICKLAS et al., 2010).

O objetivo geral do presente ensaio teórico é colocar em debate a questão dos arranjos organizacionais de biotérios em universidades públicas brasileiras. Os objetivos específicos são: 1) desenvolver uma equivalência categórica da tipologia proposta por CGEE (2003) com os arranjos organizacionais propostos por Mintzberg (2012); 2) constatar por meio de um levantamento empírico a representação dos arranjos organizacionais típicos na realidade brasileira; 3) discutir as bases de um modelo de desenvolvimento organizacional, as possibilidades e limitações dos arranjos organizacionais típicos estudados.

Para atender aos objetivos propostos, foi empregado o método tipológico (MARCONI; LAKATOS, 2005). O método tipológico é considerado específico das Ciências Sociais (WEBER, 
2004) e Ciências Sociais Aplicadas (MILLER; MINTZBERG, 1983), sendo empregado para elaborar ou desenvolver os tipos ou modelos ideias como resultado de comparações de fenômenos sociais complexos. Especificamente nesse trabalho são comparadas duas tipologias observadas na literatura. Primeiro, foi considerada a tipologia proposta pelo Centro de Gestão e Estudos Estratégicos (CGEE, 2003) o qual propõe três categorias de biotérios: 1) centros de bioterismo consolidados; 2 ) centros de bioterismo em implantação; 3) grupos emergentes em bioterismo. Com vista à realização das análises teóricas, as categorias foram comparadas com os tipos ideais de arranjos organizacionais propostos por Mintzberg (2012), quais sejam: 1) a estrutura simples; 2) a burocracia mecanizada; e 3) a adhocracia vista como rede organizacional. Estabelecida a equivalência categórica, uma prospecção foi realizada com a finalidade de constatar a representação empírica dos tipos ideais estudados na prática. Por fim, as reflexões teóricas e os dados foram empregados para propor uma discussão sobre um modelo de desenvolvimento organizacional de biotérios, possibilidades e limitações dos tipos ideias de arranjo organizacional em relação ao processo de pesquisa científica e inovação nas ciências biomédicas, biológicas e biotecnológicas. Foi uma opção dos autores a não inclusão no artigo de um tópico específico para detalhar o método considerando-se que a descrição aqui apresentada é suficiente para a compreensão do trabalho realizado. Assim sendo, enfatizou-se, no texto, a análise teórica e discussão.

O trabalho se justifica pelas contribuições para o debate a respeito de arranjos organizacionais e gestão em biotérios de universidades públicas brasileiras. Considerando que a elaboração desse artigo conjugou os aspectos teóricos e as experiências vividas, as contribuições potencialmente beneficiam o público acadêmico assim como o público ligado à prática no campo das pesquisas translacionais.

Essa introdução é seguida por uma breve apresentação dos conceitos relacionados aos biotérios e suas formas organizacionais. Na sequência, apresenta-se a análise pela qual a equivalência teórica proposta é detalhadamente apresentada. Segue-se um levantamento empírico preliminar de biotérios presentes em universidades públicas brasileiras segmentado pelo tipo de arranjo organizacional praticado. Em seguida, desenvolve-se a discussão e apresenta-se as considerações finais.

\section{REFERENCIAL TEÓRICO}

De acordo com a RN no 3, de 14 de dezembro de 2011, do Conselho Nacional de Controle de Experimentação Animal (CONCEA), os biotérios são subdivididos em a) biotério de criação; b) biotério de manutenção; c) biotério de experimentação; e d) laboratório de experimentação.

Para Hessler e Leary (2002), funcionalmente os biotérios são divididos em áreas para alojamento dos animais e áreas de suporte. A divisão do espaço físico varia entre biotérios, mas, em geral, quanto menor for o biotério, maior será a proporção da área de suporte. Nesse setor também se localiza as instalações para os agentes de saúde e higiene.

Alguns biotérios prestam serviços para cirurgia experimental e outros tipos de pesquisa em salas de cirurgia asséptica. Possibilitam procedimentos cirúrgicos em espécies de mamíferos não roedores. Possuem áreas para preparação e armazenagem de materiais estéreis, preparação cirúrgica, recuperação pós-operatória e área de armazenamento de equipamento e materiais cirúrgicos. Para os roedores, os procedimentos são menos rígidos, 
porém contam com as condições para cirurgias assépticas e possibilitam a limpeza e sanitização.

Logo, os biotérios podem ser vistos como sistemas abertos, com componentes de entradas, processamentos, saídas, retroalimentação, entropia. Katz e Kahn (1978) sugerem que as organizações apresentam características dinâmicas e caóticas, que induzem a contínua desorganização dos sistemas. É por isso que quando se cria um biotério, antes de tudo, deve-se ter claro que se cria um sistema que consome energia, na forma de energia elétrica, ração e trabalho humano e gera resíduo continuamente. Por isso, necessita a implantação de um programa de gestão consistente e efetivo, que garanta contínuo suprimento de insumos, manutenção da biossegurança, qualidade do macro ambiente, integridade das barreiras sanitárias, garantia do bem-estar animal e remoção e destino adequado do lixo gerado (ANDRADE-SILVA et al., 2012; VIANA, 2011).

Para atender suas demandas operacionais os biotérios assumem vários tipos de formas organizacionais. O exame da tipologia proposta por Mintzberg (2012) permite identificar três formas de arranjos organizacionais, a título de tipos ideais, mais frequentes dos biotérios localizados em universidades públicas brasileiras. São eles: a) os biotérios como estrutura simples; b) burocracia mecanizada; c) os biotérios como rede organizacional. O tópico seguinte apresenta uma análise teórica incluindo a apresentação dos tipos ideias e suas relações com a estruturação organizacional de biotérios em universidades públicas brasileiras.

\section{ANÁLISE TEÓRICA}

O presente tópico desenvolve equivalência categórica da tipologia proposta por CGEE (2003) considerando os arranjos organizacionais propostos por Mintzberg (2012). Para tanto, serão abordados os tipos ideias de formatos organizacionais de biotérios como estrutura simples, os biotérios como burocracia mecanizada e os biotérios como rede organizacional.

\subsection{Os biotérios como estrutura simples}

Segundo Mintzberg (2012), todas as organizações nascem como estruturas simples, caracterizadas pela supervisão direta de uma liderança carismática. São organizações com pouca ou nenhuma estrutura formal, poucos assessores de apoio, divisão de trabalho não é rigorosa, há diferenciação mínima entre suas unidades e pequena hierarquia gerencial. Pouco de seu comportamento é formalizado e faz uso mínimo do planejamento, treinamento e mecanismos de integração. Acima de tudo, trata-se de uma estrutura orgânica.

Os biotérios organizados como estruturas simples são definidos como locais onde são mantidos animais de laboratório, que possuem um responsável administrativo que, pelo fato de não estar vinculado a nenhuma estrutura mais ampla que a unidade acadêmica onde está inserido, seja a Faculdade, o Instituto ou o Departamento, acaba por tomar todas as decisões de forma isolada, embora faça parte da organização universitária.

As vantagens desse arranjo são a simplicidade operacional e a comodidade de ter sempre os animais fisicamente próximos dos pesquisadores. A autonomia propicia maior rapidez no processo de tomada de decisão e faz com que os superiores hierárquicos fiquem mais próximos, tanto fisicamente como administrativamente. Esse arranjo propicia também 
um maior sentimento de proteção e sentido de missão por partes dos usuários, que o identificam com a unidade acadêmica em questão.

No entanto, apesar de ser mais descomplicado, criar um biotério como estrutura simples pode não ser sustentável no longo prazo. As desvantagens são inúmeras, conforme discutido abaixo. Por isso, o biotério como estrutura simples deveria evoluir para outros tipos de arranjos, uma vez que a eficácia desse tipo de estrutura rapidamente entra em declínio.

A primeira desvantagem é a estagnação administrativa que pode acometer essa forma organizacional. O documento síntese do grupo de trabalho do Colégio Brasileiro de Experimentação Animal do Centro de Gestão e Estudos Estratégicos do Ministério de Ciência, Tecnologia e Inovação do Governo Federal (CGEE, 2003) propõe o estabelecimento de três categorias de biotérios: a) centros de bioterismo consolidados; b) centros de bioterismo em implantação; c) grupos emergentes em bioterismo.

Dentro da lógica proposta por CGEE (2003), um biotério administrativamente isolado, em arranjo simples, não poderia nem mesmo ser classificado como um grupo emergente. Isso porque a sua característica unitária e isolada não admite agregação a estruturas maiores. No entanto, faremos essa equivalência para fins teóricos.

O biotério como estrutura simples possui poucas condições favoráveis ao desenvolvimento organizacional em longo prazo. A estagnação gera três riscos principais.

O primeiro risco é a desatualização tecnológica pelo isolamento científico, isto é, não acompanhar a evolução da Ciência e Tecnologia para os animais de laboratório. O segundo risco é a propensão do ambiente interno do biotério isolado de se tornar insalubre, para os animais e para os homens. Para evitar a insalubridade ambiental, o controle epidemiológico da saúde dos animais é uma estratégia. O terceiro risco ocupacional real para os bioteristas é o comprometimento da saúde física por excesso de estresse.

Os conflitos em ambiente interno hostil podem se intensificar e podem gerar problemas graves para o supervisor da estrutura simples. Uma vez que não há mecanismos que proteja os administradores da exposição a ataques pessoais, os mesmos podem perder seus empregos ou, se a situação de hostilidade se perpetuar por vários anos, podem desenvolver psicopatologias que comprometam a saúde física, mental e suas relações sociais no trabalho e na sua família (DEJOURS, 2007; GUIMARÃES, 2009; JUSTICIA et al., 2007; SOARES, 2006; VIECILI; MEDEIROS, 2002).

Logo a estrutura simples é a mais arriscada das configurações quando utilizada na organização dos biotérios de médio a grande porte. Pelo fato de expor excessivamente os indivíduos, bem como personalizar suas ações, pode gerar uma grande carga de estresse sobre os supervisores e trabalhadores. E um ataque cardíaco pode, literalmente, aniquilar o principal mecanismo de coordenação da organização, a qual é centralizada na figura de apenas uma pessoa (MINTZBERG, 2012). Por isso no médio prazo surge a necessidade de integrar os biotérios arranjados como estruturas simples, para que seja possível a adequada divisão do trabalho.

\subsection{Os biotérios como burocracia mecanizada}

Um ato institucionalizado é definido como um comportamento que é realizado por dois ou mais indivíduos, persiste ao longo do tempo, e existe como uma parte do cotidiano da organização (GOODMAN; DEAN, 1982). Os princípios éticos podem ser institucionalizados 
de várias maneiras, considerando fatores de longo e de curto prazo (DUNHAM, 1984). Para o longo prazo, é recomendado às organizações o desenvolvimento de uma cultura organizacional de modo a suportar a aprendizagem e, se necessário, reaprender valores pessoais e grupais que promovam o comportamento ético da organização (SIMS, 1991).

Para institucionalizar os biotérios e, dessa forma, ajustar-se o tipo ideal da burocracia mecanizada no interior de universidades públicas no Brasil, as práticas éticas, bem como o uso dos recursos e o atendimento às exigências legais direciona a organização ao arranjo tipo guarda-chuva, ou o modelo "biotério central e biotérios setoriais". O arranjo organizacional de biotérios em universidades públicas que se ajustam ao tipo ideal da burocracia mecanizada tendem a constituir uma estrutura que contemplo uma central de biotérios. Essa configuração se caracteriza por ser uma associação institucional de biotérios, cujo propósito é criar um órgão central que será capaz de garantir o influxo de recursos financeiros de forma ininterrupta para custear a operacionalização dos mesmos e garantir um padrão arquitetônico, prevendo fluxos controlados e a criação de barreiras sanitárias.

Assim, a formação do modelo de "biotério central e biotérios setoriais" pode ser considerada como uma estratégia (formal ou emergente) para o desenvolvimento organizacional dos núcleos de bioterismo, arranjados como estruturas simples. Conforme a descrição categórica de CGEE (2003), a referida estratégia pode ser considerada como o desenvolvimento passíveis de ocorrerem pelos núcleos de bioterismo para alcançarem a condição de centros de bioterismo em formação. As vantagens do arranjo organizacional de biotérios que se ajustam ao tipo ideal da burocracia mecanizada são garantir a previsão orçamentária proposta para o órgão e absorver os impactos dos inevitáveis conflitos originados da aplicação de uma lógica administrativa, não os anulando, mas convertendo-os em oportunidades para a inovação, através da discussão dos aspectos pertinentes no conselho diretor da estrutura.

Aderente ao tipo ideal da burocracia mecanizada, essa associação deveria ser independente, como um órgão suplementar da instituição. Assim, poderiam ser suportados por um conselho diretor que teria representantes de todos os biotérios setoriais da instituição. Como há uma tendência dessa governança colegiada ser democrática, o conselho diretor também deveria incorporar as representações de usuários, docentes, pesquisadores e estudantes, bem como representantes da Comissão de Ética no Uso de Animais (CEUA) da Instituição e do responsável técnico médico-veterinário.

Por possuírem foco no suporte técnico-administrativo, as centrais de biotérios tendem a se inserem, institucionalmente, de forma transversal, em relação aos órgãos e entidades que constituem as universidades públicas. As unidades setoriais ou seccionais dos sistemas auxiliares realizam atividades e precisam observar as normas técnicas do sistema no qual está inserido e, portanto, tendem a guardar similaridade com os demais unidades setoriais.

Outra característica do tipo ideal da burocracia mecanizada aplicada aos biotérios seria a tendência de centrais de biotérios buscarem controle dos processos que constituem a estrutura como um todo. É o controle que garante que os animais produzidos ou mantidos para a experimentação animal não sejam fatores intervenientes nos processos de ensino ou pesquisa para os quais são requisitados. A própria definição do CONCEA sobre biotérios explicita o controle segundo a instrução normativa número 3, de 14 de dezembro de 2011. Portanto esse é um assunto de extrema relevância aos biotérios, às universidades e para a sociedade.

Aderente ao tipo ideal da burocracia mecanizada, a central de biotérios deveria possuir 
orçamento próprio e autonomia para decidir onde, quando e como alocar os recursos oriundos do dinheiro público e das instituições privadas. Observando a legislação e valores institucionais das universidades públicas, a inversão de recursos na estrutura institucionalizada de biotérios deveria ser apartidária, desvinculada de qualquer interesse mercantil ou econômico, no sentido de obter lucros, pois essas condições descaracterizariam a busca do bem comum e contradiriam as diretrizes das universidades públicas brasileiras.

Uma vantagem desse tipo de arranjo institucional, de acordo com o tipo ideal da burocracia mecanizada, consiste no desenvolvimento de uma cultura organizacional e na possibilidade de aplicação das práticas de gestão modernas. A visão sistêmica, ao ser aplicada ao contexto organizacional, permite a compreensão da melhor forma de gerenciamento de pessoas, materiais, espaços físicos e outros recursos. Outra possibilidade distintiva relevante, visando preservar questões éticas, consiste na possibilidade de desenvolver interações efetivas com a Comissão de Ética no Uso de Animais (CEUA).

Uma possível desvantagem desse tipo de arranjo institucional, de acordo com o tipo ideal da burocracia mecanizada, segundo Motta e Bresser-Pereira (1988), consiste na necessidade de se equalizar a centralização e a descentralização para que haja o ajuste mais eficaz das rotinas de trabalho para com seus objetivos institucionais. Essa necessidade requer recursos e energias adicionais que oneram o sistema como um todo e, não necessariamente resultam em melhorias dos serviços prestados pelas unidades de apoio.

Ainda conforme o tipo ideal da burocracia mecanizada aplicada ao biotérios, cabe ressaltar que a central de biotérios pode ser um meio eficaz para construção de uma política institucional na gestão de animais de laboratório. Na medida em que há um pacto institucional de garantir insumos aos animais alojados, na quantidade e na qualidade adequada, com estoques de segurança de ração e maravalha para no mínimo três meses, cria-se uma estabilidade alimentar de forma que os animais jamais morrerão de fome, ou de sede, no confinamento. De certa forma, tal condição pode garantir o cumprimento do dever institucional de manter os animais alojados sobre sua responsabilidade de forma seguras, limpas, saudável. Tal pressuposto pode fortalecer a posição institucional do biotério central e dos biotérios setoriais, pois aliviaria os gestores da busca de insumos necessários e estimularia o foco em atividades consideradas nobres da gestão como, por exemplo, o planejamento.

De acordo com o modelo, os biotérios setoriais prestam serviços aos pesquisadores da áreas biomédica, biológica e biotecnológica. A padronização de comportamentos por supervisão direta pode ser um fator contrário à formação de uma cultura organizacional que prevalece nas universidades públicas brasileiras, cujo modelo reforça a autonomia dos profissionais. Logo, para não se ter grande resistência, o modelo ideal da burocracia mecanizada aplicada ao biotérios deveria pressupor a autonomia dos profissionais que compõe os biotérios centrais e setoriais, sem controles excessivos e diretos. O modelo idela pressupõe a confiança nas habilidades profissionais dos componentes do sistema, que poderão propiciar o discernimento necessário para o bom ajustamento dos processos decisórios nos diferentes níveis.

Logo, para que seja possível conciliar de maneira mais ajustada as iniciativas individuais com uma coordenação central de biotérios nas universidades públicas brasileiras, o modelo ideal da burocracia mecanizada carrega, em si, o potencial de evolução para outro tipo ideal caracterizado pelo conceito de rede organizacional. Tal transição corresponderia à evolução dos centros de bioterismo em formação para que se posicionem como centro de 
bioterismo consolidado, segundo CGEE (2003). O tipo ideal da rede organizacional aplicado aos biotérios é o assunto do tópico que segue.

\subsection{Os biotérios como rede organizacional}

Para Nohria (1992), a perspectiva de rede é um modo útil de estudar organizações. 0 autor aponta três razões principais para o crescente interesse no conceito de redes nos estudos organizacionais. Primeiro, trata-se do interesse pela "nova competição" que emerge nos Estados Unidos a partir dos anos 1970 possibilitando o desenvolvimento e fortalecimento da noção de "empresa em rede" (LAZZARINI, 2008). Segundo, a perspectiva de rede é estimulada também pelos desenvolvimentos tecnológicos de informação e comunicação (TIC) e seus impactos na sociedade, economia e organizações (CASTEL, 1999). Terceiro, a perspectiva também é fortalecida pelo amadurecimento da análise de rede como uma disciplina acadêmica ao longo do mesmo período (NOHRIA; ECCLES, 1992; WASSERMAN; FAUST, 1994).

A definição de rede é a totalidade de todas as unidades conectadas por certo tipo de relacionamento (JAY, 1964). Segundo Motta (1987), as redes se constituem das unidades organizacionais e das ligações que existem entre elas. São constituídas para facilitar a aquisição de recursos como equipamentos, dinheiro, conhecimento técnico, usuários e fornecedores (PORTER; POWELL, 2006).

As redes são analisadas utilizando vários indicadores, instrumentos e métodos (WASSERMAN; FAUST, 1994). Segundo Machado e Ipiranga (2013), os principais fatores são o número de conexões existente na rede, o número de atores que estão diretamente relacionados a uma pessoa, qual pessoa tem o papel mais central na rede, as possibilidades de integração que uma pessoa pode exercer na comunicação entre os nós da rede e a possibilidade que um ator possui para acessar todos os outros nós da rede.

As características estruturais das redes são tão importantes pela sua atividade quanto o desenvolvimento histórico das ligações existentes entre as organizações integrantes. Motta (1987) define as ligações das redes como acoplamento frouxo e folgado, como é na maioria das organizações educacionais onde a autonomia prevalece, ou firme e estreito, como são as organizações militares, onde a obediência e a formalização prevalecem. Elas são ubíquas e um fator crítico na vida organizacional (PORTER; POWELL, 2006).

As redes de acoplamento frouxo, como não são baseadas em regras de obediência e respeitam a autonomia de cada integrante, ou nó, pode ser bem sucedida como uma estratégia de governança dos biotérios dentro das universidades públicas brasileiras, pois a relação é estabelecida com base no relacionamento, pelo compromisso, pela reputação e confiança.

Do ponto de vista da adaptação e mudanças o tipo ideal da rede organizacional como estrutura administrativa supera os limites dos arranjos institucionais baseados nos modelos da estrutura simples e da burocracia mecanizada. Ela possibilita o compartilhamento de conhecimentos de forma mais rápida, pois possui capilaridade em toda a rede, e não apenas na cúpula administrativa, ou em um determinado grupo de profissionais. É dinâmico, pois o diálogo e a negociação entre os indivíduos que a constituem possibilita avançar nas questões que demandam consenso, respeitando a autonomia de cada biotério.

Ela pode ser gerenciada como uma adhocracia, segundo Mintzberg (2012). Nesse tipo de arranjo organizacional, o principal mecanismo de coordenação é o ajustamento mútuo 
em uma estrutura matricial. Ao se ajustar ao tipo ideal da rede organizacional, todos os biotérios de uma instituição, por exemplo, podem estar envolvidos em um projeto de monitoramento sanitário coordenado pelos responsáveis de dois biotérios específicos. Paralelamente outros biotérios da Instituição podem estar envolvidos em um projeto de criopreservação de embriões, por exemplo, que abranja apenas os biotérios de criação, e não envolva os biotérios de experimentação. Logo, essa estrutura não se baseia na obediência inquestionável, mas sim no entendimento inteligente e competente.

Segundo Porter e Powell (2006), o compartilhamento de tarefas complementares pode ser uma razão de existir de uma rede organizacional. Esta pode, por exemplo, terceirizar a parte operacional, alugar depósitos de ração e maravalha, contratarem os serviços de consultoria de outros profissionais para resolver problemas operacionais e administrativos, contratar os controles de um laboratório que monitore a saúde e a genética dos animais de outra instituição.

Além de ser consumidora, a rede pode também ofertar assessoria de apoio operacional. Por possuir muita especialização horizontal e oferecer muito treinamento aos integrantes da rede, com unidades pequenas seletivamente descentralizadas, os membros também podem, individualmente, ofertar outros serviços e produtos a outros biotérios dentro e fora da rede.

A rede pode ser um arranjo organizacional favorável aos bioteristas, aos pesquisadores e à criatividade científica. Heinze et al. (2009) associaram a ciência criativa com grupos pequenos, contextos organizacionais que permitam acesso a uma variedade de habilidades técnicas complementares, estabilidade do financiamento das pesquisas, consultoria periódica de habilidades e recursos fora dos muros da Instituição e liderança facilitada. Todas essas condições podem ser oferecidas pela rede.

A desvantagem da rede, paradoxalmente, é a sua ambiguidade. O biotério é livre para não aceitar as determinações da coordenação central da rede, embora sejam sempre sujeitos à legislação e às normas vigentes. A qualquer momento ele pode se desligar da rede, caso julgue que a condição de trabalho isolado seja necessária ou vantajosa. Portanto esses, e outros, fatores condicionantes podem interferir na integração com redes concebidas em outras Instituições para prestação de serviços tecnológicos para laboratórios de pesquisa na área da biomedicina, conforme exposto por Teixeira (2012).

\section{LEVANTAMENTO EMPÍRICO}

Por meio da análise de 436 instituições credenciadas no Credenciamento Institucional para Atividades com Animais em Ensino (CIAEP/CONCEA), que figuraram na lista confeccionada pela Secretaria Executiva do Órgão em novembro de 2016, disponível em SBCAL/COBEA (2016), é possível descrever características da distribuição dos biotérios brasileiros, conforme encontra-se representado na Figura 1.

Há uma distribuição desigual das instituições cadastradas pelo CONCEA. Os estados brasileiros que possuem mais instituições credenciadas são, por ordem decrescente, São Paulo (36 \%); Minas Gerais (12,4\%); Rio Grande do Sul (7,6 \%); Rio de Janeiro (6,9\%); Paraná $(6,4 \%)$ e Santa Catarina (2,9\%). Logo as macrorregiões sul e sudeste concentram quase a totalidade das instituições cadastradas (74,25\%).

A maior parte das instituições de ensino público no Brasil possuem biotérios. De acordo com SBCAL/COBEA (2016), em novembro de 2016 havia 128 universidades e 
faculdades públicas credenciadas pelo CONCEA. Destas, 104 foram identificadas com descritores de instalações animais. No entanto, os arranjos organizacionais desses biotérios variam muito em função da macrorregião considerada.

Dentre os biotérios credenciados nas instituições brasileiras de ensino público superior, a análise dos dados indicou que os arranjos organizacionais mais frequentes são do tipo burocracias mecanizadas. Esse arranjo organizacional representa 53,8\% do total de instituições credenciadas com instalações animais. Os maiores números de instituições cadastradas nesse arranjo se localizam na região Sudeste $(60,7 \%, n=34)$, na sequência, a região Sul $(17,9 \% ; n=10)$, a região nordeste $(14,3 \% ; n=8)$, a região Centro-Oeste $(3,6 \% ; n=2)$ e a região norte $(3,6 \% ; n=2)$.

As estruturas simples representam o segundo tipo de arranjo mais frequente, sendo 25,0\% dos arranjos organizacionais dos 104 biotérios brasileiros presentes nas Instituições de Ensino Superior Público, credenciadas no CONCEA. O maior número de instituições cadastradas com esses tipos de arranjos está localizado na região Nordeste $(34,6 \%, n=9)$, na sequência, região Norte $(23,1 \% ; n=6)$, a região Sul $(23,1 \% ; n=6)$, a região Centro-Oeste $(11,5 \% ; n=3)$; e por último a região sudeste $(7,7 \% ; n=2)$.

Figura 1- Distribuição de solicitações de credenciamento ao CONCEA por localidade. 


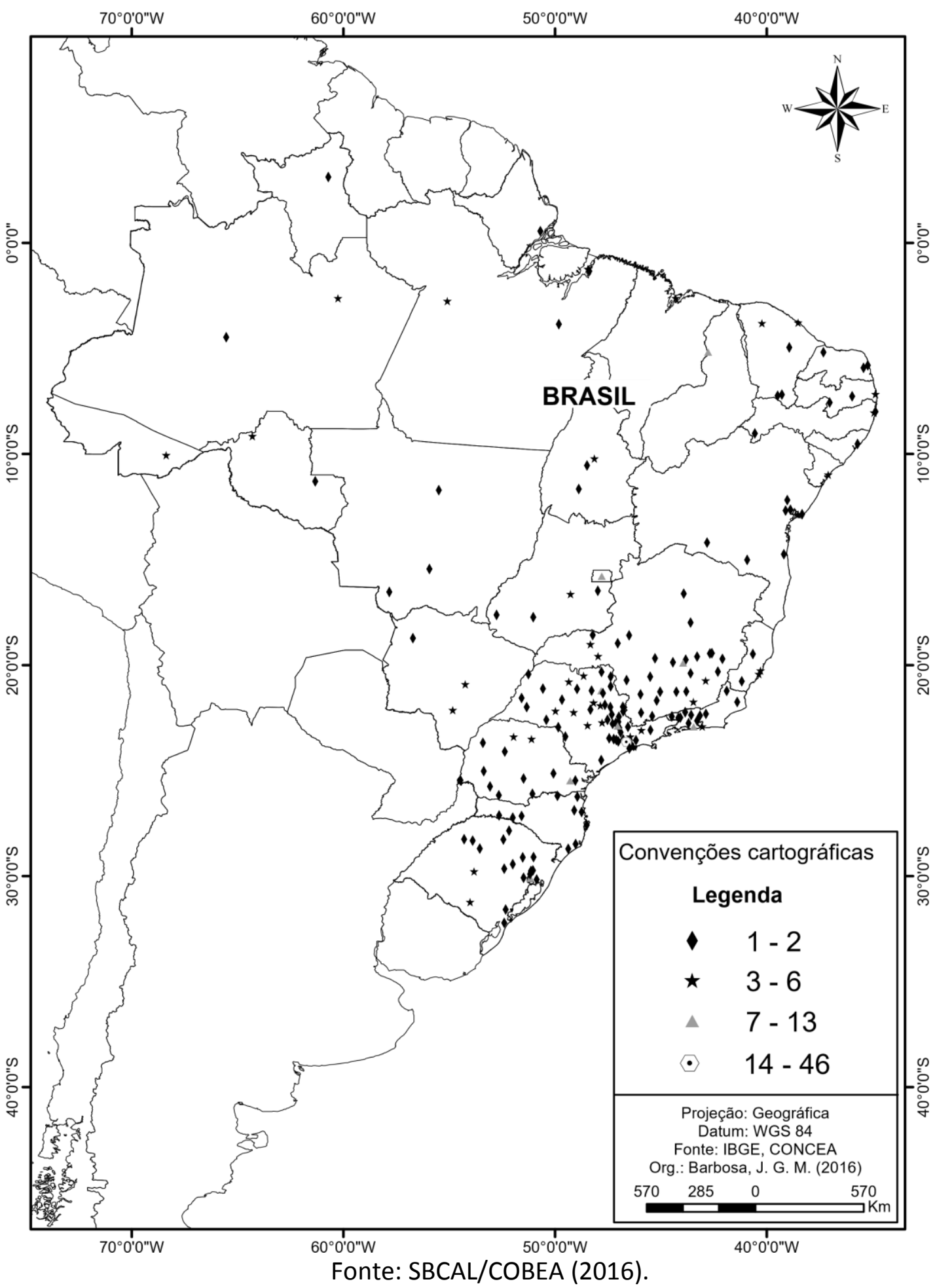

A rede organizacional interna é o tipo ideal menos frequente de arranjos organizacionais verificados em biotérios nas universidades públicas brasileiras. A região Sudeste apresenta 21 instituições credenciadas (95,5\%) nesse tipo de arranjo e o Sul apresenta apenas uma instituição (4,5\%). Os 22 biotérios em forma de rede organizacional em universidades públicas brasileiras representam $21,2 \%$ dos biotérios presentes nas instituições de ensino superior que possuem biotério. Não foi verificado esse arranjo nas demais regiões do país. Os dados estão sumarizados na Figura 2 
Figura 2- Distribuição Regional dos Arranjos Organizacionais de Biotérios em Instituições de Ensino Públicas Brasileiras

\begin{tabular}{|c|c|c|c|c|c|c|}
\hline \multirow[t]{2}{*}{ Arranjo Organizacional } & \multicolumn{5}{|c|}{ Macrorregião brasileira (\%) } & \multirow{2}{*}{ Total (\%) } \\
\hline & $\mathrm{N}$ & NE & $\mathrm{CO}$ & $\mathrm{S}$ & SE & \\
\hline Burocracia mecanizada & $2(3,6 \%)$ & $8(14,3 \%)$ & $2(3,6 \%)$ & $10(17,9 \%)$ & $34(60,7 \%)$ & $56(53,8 \%)$ \\
\hline Estrutura simples & $6(23,1 \%)$ & $9(34,6 \%)$ & $3(11,5 \%)$ & $6(23,1 \%)$ & $2(7,7 \%)$ & $26(25,0 \%)$ \\
\hline Rede organizacional & $0(0,0 \%)$ & $0(0,0 \%)$ & $0(0,0 \%)$ & $1(4,5 \%)$ & $21(95,5 \%)$ & $22(21,2 \%)$ \\
\hline Total (\%) & $8(7,7 \%)$ & $17(16,3 \%)$ & $5(4,8 \%)$ & $17(16,3 \%)$ & $57(54,8 \%)$ & $104(100 \%)$ \\
\hline
\end{tabular}

Fonte: elaborado pelos autores com base em SBCAL/COBEA (2016).

\section{DISCUSSÃO}

Discutiremos alguns aspectos pertinentes às formas organizacionais apresentadas. A Figura 3 compara as formas de interação entre os biotérios institucionais entre os três tipos de arranjos ideais discutidos.

A Figura 3A apresenta o tipo ideal de biotérios sob a forma organizacional de estrutura simples, sua representação empírica se caracteriza por serem isoladas atendendo os projetos de cada pesquisador, localizados internamente. Os resultados indicam que $25 \%$ dos biotérios localizados no interior de universidades públicas brasileiras adotam esse tipo ideal.

A Figura 3B representa o tipo ideal de biotério sob a forma organizacional de burocracia mecanizada, sua representação empírica tipicamente se caracteriza por serem compostos de um biotério central e biotérios setoriais hierarquicamente subordinados. Os resultados indicam que $53,8 \%$ dos biotérios da base estudada se ajustam ao tipo ideal da burocracia mecanizada.

A Figura $3 C$ apresenta o tipo ideal de biotério em formato de rede organizacional. Suas representações empíricas se caracterizam por serem compostas por projetos exclusivos de um biotério integrado à rede ou por operarem por meio de projetos compartilhados por mais de um biotério da rede, conforme indica as setas que transcendem a unidade, podendo alcançar uma abrangência de múltiplos biotérios integrados à rede. Nesse caso, o tipo ideal estudado indica que, em suas representações empíricas, os recursos financeiros e os conhecimentos mobilizados pelos projetos, provavelmente, são adquiridos e distribuídos por gestores da rede organizacional, em condições negociadas conforme prioridade acordada dentro da rede organizacional.

Os padrões de interações estão relacionados com o desenvolvimento organizacional de biotérios. Esse ponto pode ser discutido considerando os biotérios como sistemas abertos e que possuem a propriedade da equifinalidade, isto é, não há maneiras certas e únicas para a administração e a organização de atividades (MOTTA, 1987). Por isso, podem existir, concomitantemente, na mesma instituição biotérios como arranjos simples, biotérios como burocracias mecanizadas e biotérios em rede.

Esses arranjos são dinâmicos e reformulados de acordo com as exigências operacionais e da cultura organizacional. Uma exigência que a sociedade e a comunidade acadêmica faz é que os biotérios em universidades públicas brasileiras sejam organizações eficazes e éticas.

No entanto, dependendo dos arranjos organizacionais assumidos, há uma maior possibilidade de desenvolvimento organizacional dos biotérios que em outros, por meio de 
investimentos contínuos de recursos financeiros associados a uma política institucional. Isso beneficia todos os componentes do sistema por aumentar a eficiência e a eficácia dos biotérios, a consciência ética no ambiente de trabalho, a institucionalização dos biotérios e os padrões de qualidade dos animais alojados, refletindo na produção científica e na inovação tecnológica institucional. Portanto, consideramos que a busca do desenvolvimento organizacional é um esforço extremamente relevante.

Uma visão da possível trajetória para o desenvolvimento dos biotérios nas universidades públicas brasileiras está sintetizada na Figura 4. De acordo com essa visão, o arranjo organizacional considerado menos desenvolvido seria a estrutura simples localizada na base da trajetória representada. A mais evoluída seria a rede organizacional. A burocracia mecanizada seria uma estrutura intermediária.

Figura 3 - Representações de Formas Organizacionais de Biotérios e suas Interações

Figura 3.A - Estrutura simples (grupos emergentes de bioterismo)

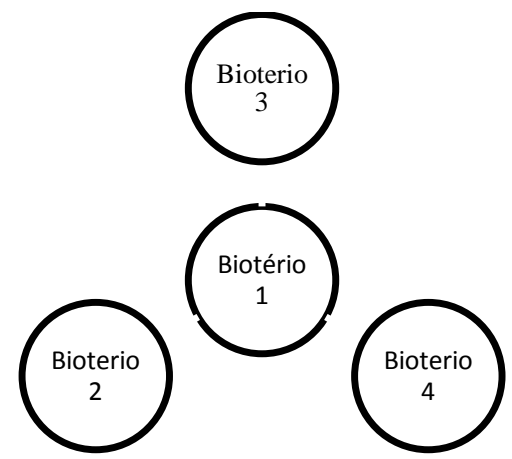

Figura 3.B - Burocracia mecanizada (centros de bioterismo em formação)

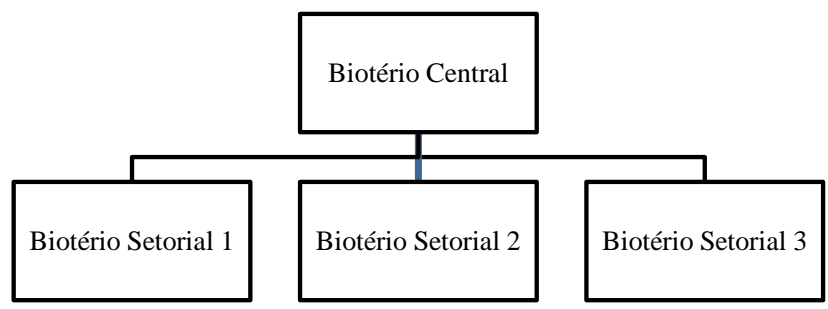

Figura 3.C - Rede Organizacional (centros de bioterismo consolidados)

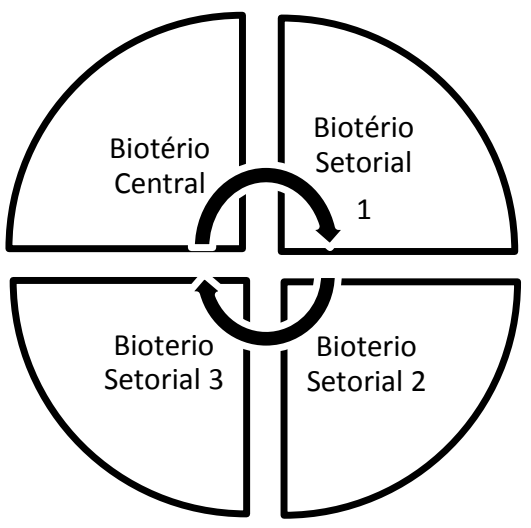


Fonte: os autores.

De acordo com PCAST (2012), a investigação e o desenvolvimento de novas drogas e terapias estão em declínio, apesar de no último quarto do Século XX ter havido um enorme avanço no conhecimento originado da pesquisa biomédica para a compreensão de doenças como câncer, doenças do coração, diabetes e outras doenças devastadoras. A translação do conhecimento obtido na bancada dos laboratórios para o leito dos pacientes está cada vez mais difícil. Talvez o uso de arranjos organizacionais adequados a cada situação particular e ao seu contexto, seja um dos fatores que pode ajudar a reverter essa tendência.

Figura 4 - Trajetória para o Desenvolvimento Organizacional de Biotérios nas Universidades Públicas Brasileiras

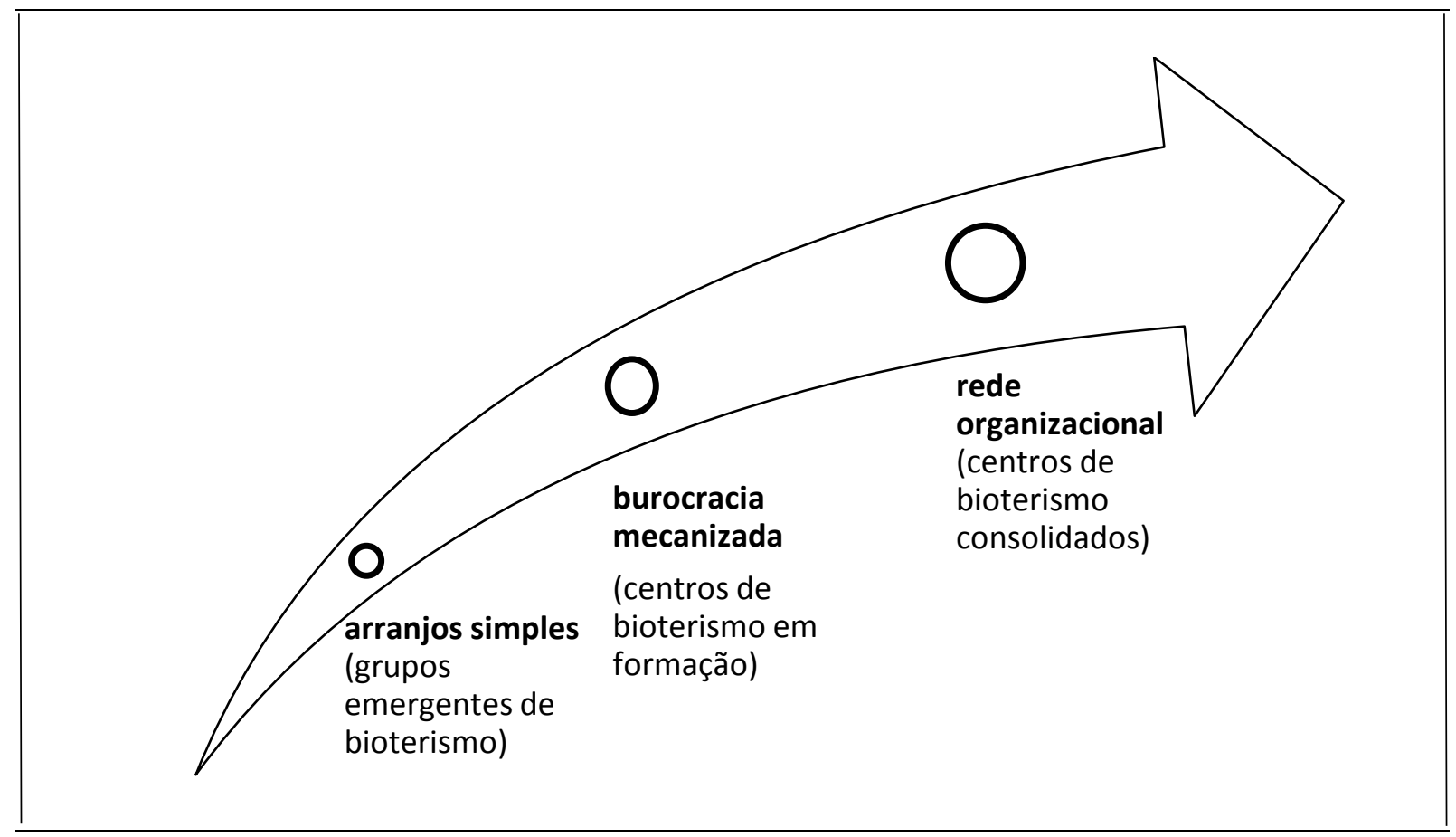

Fonte: os autores.

Weber (2013) desenvolveu um método para avaliar a distância da translação entre os dados obtidos por meio de animais em biotérios e o tratamento de seres humanos, denominado "Triângulo da Biomedicina". O autor demonstra que tópicos importantes da pesquisa biomédica têm utilizado os modelos animais associados ao uso de ferramentas celulares e moleculares. Isso tem diminuído o tempo de translação do conhecimento obtido para o seu uso na clínica médica. Portanto, novas tecnologias, se forem bem gerenciadas, podem colaborar para as melhorias no processo de translação.

Hobin et al. (2012) sugerem que um ambiente de pesquisa translacional de sucesso requer muitas pessoas diferentes, treinadas em muitas disciplinas, trabalhando dentro de uma estrutura que promova a interação entre aqueles que têm compreensão clínica da saúde e da doença humana e aqueles que têm formação e especialização em biologia fundamental, os mecanismos moleculares de doença, e a utilização de modelos animais.

Biotérios eficazes buscam preservar o ambiente que propicie a translação. Com a gestão dos conflitos internos e externos as instituições promovem a interdisciplinaridade e o 
trabalho coletivo na busca do bem comum. Os arranjos organizacionais adequadamente utilizados podem estimular a motivação das pessoas para trabalharem nos biotérios e garantir bom ambiente de trabalho e interação, desenvolvendo as oportunidades e respeitando as limitações pessoais e organizacionais, mas acima de tudo, estimulando a criação e a perpetuação de biotérios eficazes nas universidades públicas brasileiras.

Finalmente, desejamos sintetizar as possibilidades e limitações dos arranjos organizacionais teóricos aplicados aos biotérios, considerando as contribuições para a pesquisa científica e a inovação no campo das ciências biomédicas, biológicas e biotecnológicas. Em especial, desejamos debater de que maneira os arranjos organizacionais poderão beneficiar os avanços da pesquisa translacional nas universidades públicas brasileiras.

Os biotérios organizados segundo a estrutura simples apresentam como possibilidade uma destacada simplicidade operacional que se contrapõem à limitação determinada pelo isolamento administrativo, exposição dos seus gestores e trabalhadores e a personalização das ações que poderá beneficiar o desenvolvimento da pesquisa e da inovação até certo ponto de sua trajetória desde que as demandas sejam relativamente simples e envolvam poucos interesses divergentes e pluralidade de especialidades. Em contraposição, tal condição poderá representar alto nível de ineficiência e estagnação a partir do momento em que o biotério experimenta crescimento e demandas mais complexas. Em relação à pesquisa translacional, o biotério organizado segundo a estrutura simples conta com poucas possibilidades de contribuir com os avanços requeridos devido ao seu isolamento, ações personalizadas e limitada diversidade de especializações.

Os biotérios que se organizam conforme o arranjo organizacional da burocracia mecanizada pode ser capaz de maximizar o uso de recursos por meio da padronização, formalização de controles e de procedimentos. Essas características poderão resultar em maior eficiência e produtividade da estrutura. No entanto, é possível que experimentem rigidez e padronização excessiva resultando em morosidade no atendimento das demandas. Tal morosidade pode ser negativa em algumas circunstâncias, mas não inviabiliza as contribuições significativas para o avanço da pesquisa translacional. $O$ acesso mais amplo a recursos e a maximização dos seus usos combinada com a formalização de controles e procedimentos eficientes potencializam as contribuições significativas para o atendimento de demandas complexas.

No que tange às contribuições ao avanço da pesquisa científica e da inovação no campo da pesquisa translacional, os biotérios que se organizam conforme o modelo analisado da rede organizacional poderão trazer as maiores contribuições sob a forma de adaptações ao ambiente dinâmico. No entanto, tal arranjo organizacional demanda um ambiente amplamente institucionalizado e considerável capacidade de gestão e coordenação que extrapolam os limites organizacionais. Pode-se identificar preliminarmente um conjunto de possibilidades vinculadas à flexibilidade administrativa sem abrir mão da formalização de controles e procedimentos impostos por leis e normas instituídas. Também conta a favor uma maior agilidade no acesso ao conhecimento científico. No entanto, a maior articulação política na busca do ajustamento mútuo pode prolongar o processo de tomada de decisões.

A Figura 5 sintetiza as possibilidades e limitações de arranjos organizacionais para biotérios em universidades públicas brasileiras. 
Figura 5- Possibilidades e Limitações de Arranjos Organizacionais de Biotérios em Universidades Públicas Brasileiras

\begin{tabular}{|l|l|l|}
\hline Arranjo Organizacional & Possibilidades & Limitações \\
\hline Estrutura simples & $\begin{array}{l}\text { Simplicidade operacional; } \\
\text { Agilidade no atendimento das } \\
\text { demandas simples. }\end{array}$ & $\begin{array}{l}\text { Isolamento administrativo; } \\
\text { exposição individual e } \\
\text { personalização de ações. }\end{array}$ \\
\hline Burocracia mecanizada & $\begin{array}{l}\text { Maximização do uso de recursos; } \\
\text { Formalização de controles e de } \\
\text { procedimentos. }\end{array}$ & $\begin{array}{l}\text { Rigidez e padronização excessivas; } \\
\text { Morosidade no atendimento das } \\
\text { demandas. }\end{array}$ \\
\hline Rede organizacional & $\begin{array}{l}\text { Flexibilidade administrativa e } \\
\text { rápido acesso ao conhecimento } \\
\text { científico. }\end{array}$ & $\begin{array}{l}\text { A maior necessidade de } \\
\text { articulação política pode prolongar } \\
\text { o processo de tomada de decisões. }\end{array}$ \\
\hline
\end{tabular}

Fonte: os autores.

\section{CONSIDERAÇÕES FINAIS}

O objetivo geral do presente trabalho é colocar em debate a questão dos arranjos organizacionais de biotérios em universidades públicas brasileiras. Os objetivos específicos são: 1) desenvolver uma equivalência categórica da tipologia proposta por CGEE (2003) com os arranjos organizacionais propostos por Mintzberg (2012); 2) constatar, por meio de um levantamento empírico, uma representação dos arranjos organizacionais típicos na realidade brasileira; 3) discutir as bases de um modelo de desenvolvimento organizacional, as possibilidades e limitações dos arranjos organizacionais típicos estudados. Atendemos aos objetivos propostos na medida em que apresentamos um referencial teórico focado nos principais arranjos organizacionais presentes nas universidades públicas brasileiras discutindo as suas limitações e potencialidades. Também apresentamos uma análise teórica de três tipos ideais de arranjos organizacionais relacionados à estruturação dos biotérios em universidades públicas brasileiras: 1) os biotérios como estrutura simples; 2) os biotérios como burocracia mecanizada; 3 ) os biotérios como rede organizacional. A análise teórica apresentou os tipos ideias incluindo seus aspectos de estruturação e gestão.

Um levantamento empírico preliminar permitiu constatar a existência prática dos tipos ideias dos arranjos organizacionais de biotérios em universidades públicas brasileiras, assim como mapear a sua distribuição regional considerando as referidas categorias teóricas.

A discussão envolveu as formas de biotérios institucionais e suas interações, uma possível trajetória para o desenvolvimento organizacional de biotérios e uma síntese das possibilidades e limitações de arranjos organizacionais de biotérios em universidades públicas brasileiras, considerando as expectativas de avanços da pesquisa científica, inovação e, em especial, os requisitos necessários para o desenvolvimento de uma melhor pesquisa translacional.

As conclusões do trabalho referem-se a quatro elementos abrangidos pelo presente estudo: 1) as formas organizacionais de biotérios em universidades brasileira; 2) uma possível trajetória para o desenvolvimento organizacional de biotérios em universidades públicas brasileiras; 3 ) as principais possibilidades atribuídas de arranjos organizacionais de biotérios em universidades públicas brasileiras; 4) as principais limitações de arranjos organizacionais de biotérios em universidades públicas brasileiras.

Conclui-se que os biotérios em universidades públicas brasileiras organizam-se principalmente conforme três formas ideias: 1 ) os biotérios vistos como estrutura simples; 2) 
os biotérios como burocracia mecanizada; 3 ) os biotérios vistos como rede organizacional.

Os três tipos ideais podem ser entendidos como integrantes de uma trajetória para o desenvolvimento organizacional dos biotérios em universidades públicas brasileiras ao longo do tempo. De acordo com essa visão, o arranjo organizacional considerado básico é aquele que se fundamenta no tipo ideal da estrutura simples. De acordo com nossa visão, esta forma organizacional típica estaria localizada na origem da trajetória de um biotério conforme apresentado na Figura 4. O formato organizacional considerado mais evoluído e com melhor capacidades adaptativas em relação ao ambiente dinâmico das pesquisas translacionais é aquele baseado no tipo ideal de biotério visto como rede organizacional. Assim sendo, o tipo ideal de formato organizacional de biotério visto como burocracia mecanizada poderia ser considerado como uma estrutura intermediária no processo de desenvolvimento organizacional ao longo da trajetória organizacional dos biotérios. Visto dessa forma, considerando as discussões sobre a estruturação de biotérios em universidades públicas brasileiras, a estrutura burocrática é vista como transitória, sendo a estruturação pós-burocrática o destino principal do processo de desenvolvimento organizacional.

Cada tipo ideal na prática carrega um conjunto de possibilidades e limitações a serem observado na sua gestão.

Este trabalho apresenta limitações. Trata-se de um ensaio teórico baseado na experiência e observação de seus autores e a integração de referencial teórico específico dos campos das Ciências Biomédicas e Administração. Consideramos que este trabalho consiste num esforço preliminar para desenvolver uma pesquisa transdisciplinar capaz de desvendar as condições específicas de funcionamento dos biotérios de universidades federais brasileiras em termo da prática de gestão e formato organizacional. Não foi possível incorporar até o momento a visão mais aprofundada dos diferentes atores que compõe a arena em análise, embora se reconheça a sua existência na formação de um ambiente complexo e dinâmico.

Sugere-se o desenvolvimento de pesquisas empíricas para a produção de conhecimento sobre os arranjos organizacionais adotados por biotérios de universidades públicas brasileiras e, assim, contribuir significativamente com o debate em curso a respeito do tema. Em primeiro lugar, sugere-se o desenvolvimento de estudos de caso múltiplos baseado na tipologia proposta por permitirem a comparação das evidências empíricas e aprofundar as análises teóricas e empíricas. Em segundo lugar, sugere-se a realização de estudos de caso únicos para compreender e avaliar os formatos organizacionais que constituem exceções aos tipos ideias estudados ao longo deste artigo. Em terceiro lugar, indica-se o grande interesse de estudos de biotérios em universidades públicas como redes organizacionais de maneira a incluir as metodologias e instrumentos típicos do campo da análise de redes organizacionais (NOHRIA; ECCLES, 1992; WASSERMAN; FAUST, 1994). Por fim, indica-se a necessidade de pesquisas sobre o campo institucional envolvendo os biotérios que operam nas universidades públicas brasileiras.

Espera-se que este trabalho traga significativas contribuições ao campo da pesquisa translacional e para o debate a respeito de prática de gestão e formatos organizacionais de biotérios em universidades públicas brasileiras.

\section{REFERÊNCIAS}


ALONSO, F. R.; LÓPEZ, F. G.; CASTRUCCI, P. L. Curso de Ética em Administração: Empresarial e Pública. 3a. ed. São Paulo: Atlas, 2012.

ANDRADE-SILVA, B. E. et al. Monitoramento dos pontos críticos relativos à biossegurança, barreiras sanitárias e macroambiente do biotério de experimentação do pavilhão Leônidas Deane - IOC/FIOCRUZ, RESBCAL, v.1, n.2, p. 195-200, 2012.

BAYNE, K. A. Animal care and use programs: Global harmonization through alternatives. AATEX, v. 14, special issue, p. 749-752, 2008.

BAYNE, K.; MILLER, J. G. Assessing animal care and use programs internationally. Lab Animal, v.29, n. 6, p. 27-29, 2000.

BRAGA, L. M. G. M. O Animal como Modelo Experimental: noções básicas de genética, sanidade, alojamento e manutenção de animais de laboratório. In: FEIJÓ, A. G. S.; BRAGA, L. M. G. M.; PITREZ, P. M. C. (Ed.). Animais na Pesquisa e no Ensino: aspectos éticos e técnicos. Porto Alegre: EDIPUCRS, 2010. p. 171-186. Disponível em:

<http://books.google.com.br/books/about/ANIMAIS_NA_PESQUISA_E_NO_ENSINO.html?id =wTHTkgUmqqAC $>$, acesso em: 05/09/2014.

BRUNE, K. Animal Experimentation in Sciences: Sadistic Nonsense or Indispensable Necessity? Altex, v.19, n.3, p. 130-136, 2002.

CASTELLS, M. A Sociedade em Rede. São Paulo, SP: Paz e Terra, 1999.

CERQUEIRA, N. Métodos alternativos ainda são poucos e não substituem totalmente o uso de animais. Ciência e Cultura, v.60, n. 2, p. 47-49, 2008.

CGEE. Programa de Ação para Biotérios: Documento Síntese. São Paulo: Centro de Gestão e Estudos Estratégicos (CGEE), 2003

DEJOURS, C. A. Banalização da Injustiça Social. Rio de Janeiro: Editora FGV, 2007.

DEMERS, G. et al. Harmonization of Animal Care and Use Guidance. Science, v. 312, p. 700701, 2006.

DUNHAM, R. B. Organizational Behaviour: People and Processes in Management. Homewood, III: Irwin, 1984.

FESTING, M. F. W., et al. Reducing the Use of Laboratory Animals in Biomedical Research: Problems and Possible Solutions. The Report and Recommendations of ECVAM Workshop 29. ATLA, v.26, p. 283-301, 1998.

GOLDBERG, A. M. Use of Animals in Research: A Science - Society Controversy? The American Perspective: Animal Welfare Issues. Altex, v.19, n.3, p.137-139, 2002. 
GOODMAN, P. S.; DEAN, J.W. Jr. Creating long-term organizational change. In: GOODMAN, P. S.; Associates (Ed.), Change in Organizations. San Francisco: Jossey-Bass Publishers, 1982. p. 226-279.

GUIMARÃES, M. C. Transformações do trabalho e violência psicológica no serviço público brasileiro. Revista Brasileira de Saúde Ocupacional.v. 34, n. 120, p.163-171, 2009.

HEINZE, T et al. Organizational and institutional influences on creativity in scientific research. Research Policy, v. 38, n.4, p. 610-623, 2009.

HESSLER, J. R.; LEARY, S. L. Design and management of animal facilities. In: FOX et al. (Ed.). Laboratory Animal Medicine. California, USA: Academic Press, 2002. p. 909-953.

HOBIN, J. et al. Engaging basic scientists in translational research: identifying opportunities, overcoming obstacles. Journal of Translational Medicine, v.10, n. 72, p. 1-14, 2012.

JAY, E. J. The Concepts of "Field" and "Network" in Anthropological Research. Man, v.64, p. 137-139, 1964.

JUSTICIA, F. J., et al. El fenómeno del acoso laboral entre los trabajadores de la universidad. Psicologia em Estudo, n. 12, n. 3, p. 457-463, 2007.

KATOH, H. International Harmonization of Laboratory Animals. In: International Committee of the Institute for Laboratory Animal Research (Ed.). Microbial Status and Genetic Evaluation of Mice and Rats: Proceedings of the 1999 US/Japan Conference. Washington, D.C: National Academy Press, 2000. p. 85-96.

KATZ, D.; KAHN, R. L. The Social Psychology of Organizations. 2nd. ed. New York: John Wiley Sons, 1978.

LAZZARINI, s. g. Empresa em Rede. São Paulo, SP: Cengage Learning, 2008.

LAUZ, S. et al. A importância dos biotérios na pesquisa experimental. Vittalle, Rio Grande, v. 20, n. 1, p. 25-29, 2008.

MACRINA, F. L. Scientific societies and promotion of the responsible conduct of research: codes, policies, and education. Acad. Med. , v. 82, n. 9, p. 865-869, 2007.

MACHADO, Q.; IPIRANGA, A. Characteristics and performance of knowledge networks in the biotechnology sector. Revista de Administração Contemporânea, v. 17, n. 3, p. 350-367, 2013.

MASSIRONI, S. M. G. Padrão Genético. In: LAPCHIK, V. V.; MATTARAIA, V. M.; KO, G. M. (Ed.). Cuidados e Manejos de Animais de Laboratório. São Paulo:Atheneu, 2010. p. 385-398. 
MINTZBERG, H. Criando organizações eficazes: estruturas em cinco configurações. 2. ed. São Paulo: Atlas, 2012.

MILLER, D.; MINSTZBERG, H. The Case for Configuration. In: MORGAN, G (ed.). Beyond Method: Strategies for Social Research. Newbury Park, CA; London, UK; New Delhi, IND: Sage Publication, 1983, cap. 4, p. 57-73.

MOTTA, F. C. P. Redes organizacionais e estado amplo. Revista de Administração de Empresas, v.27, n. 2, p. 5-13. 1987.

MOTTA, F. C. P., ; Bresser-Pereira, L. C. Introdução à Organização Burocrática. São Paulo: Brasiliense.1988.

MUSCHLER, G. F. et al. The Design and Use of Animal Models for Translational Research in Bone Tissue Engineering and Regenerative Medicine. Tissue Engineering Part B: Reviews, v. 16, n. 1, p. 123-145, 2010.

NICKLAS, W. et al. FELASA guidelines for the accreditation of health monitoring programs and testing laboratories involved in health monitoring. Lab Animal, v. 39, n. 2, p. 43-48. 2010.

NOHRIA, N. Introduction: Is a Network Perspective a Useful Way of Studing Organizations? In: NOHRIA, N.; ECCLES, R. G. (ed.) Networks and Organizations: Structure, Form, and Action. Boston, Massachusetts: Harvard Business School Press, 1992, Introduction, p. 1-22.

NOHRIA, N.; ECCLES, R. G. (ed.) Networks and Organizations: Structure, Form, and Action. Boston, Massachusetts: Harvard Business School Press, 1992.

PCAST (The President's Council of Advisors on Science and Technology). Report to the President on Propelling Innovation in Drug Discovery, Development, and Evaluation. Washington, DC. 2012. Relatório.

PORTER, K. A.; POWELL, W. W. Networks and Organizations. In S. R. Clegg, C. Hardy, T. B. Lawrence; W. R. Nord (Ed.), The SAGE Handbook of Organization Studies. London, Thousand Oaks, New Delhi: Sage Publication, 2006. p. 776-799.

PRESGRAVE, O. A. F. Alternativas para animais de laboratório:do animal ao computador. In: ANDRADE, A.; PINTO, S. C.; OLIVEIRA, R. (Org.). Animais de Laboratório: criação e experimentação [online]. Rio de Janeiro: Editora FIOCRUZ, 2002. P. 361-367. Disponível em: http://books.scielo.org/id/sfwtj/44, acesso em 04/09/2014.

QUEVEDO, J., et al. Pesquisa Translacional em medicina. Revista de Pesquisa e Extensão em Saúde, v. 4, n. 1, p. 2-21. 2008.

RIVERA, E. A. B. Bem-estar na experimentação animal. In: FEIJÓ, A. G. S.; BRAGA, L. M. G. M.; PITREZ, P. M. C. (Ed.). Animais na Pesquisa e no Ensino: aspectos éticos e técnicos [online]. 
Porto Alegre: EDIPUCRS, 2010. p. 74-88. Disponível em:

http://books.google.com.br/books/about/ANIMAIS_NA_PESQUISA_E_NO_ENSINO.html?id= wTHTkgUmqqAC, acesso em: 05/09/2014.

ROLLIN, B. E. Animal Mind: Science, Philosophy, and Ethics. The Journal of Ethics, v.11, n. 3, p. 253-274, 2007.

Animal Pain: What It is and Why It Matters. The Journal of Ethics, v.15, n. 4, p.

425-437, 2011.

RUSSELL, W. M. S.; BURCH, R. L. The Principles of Humane Experimental Technique. London: Universities Federation for Animal Welfare, 1959/1992.

SBCAL/COBEA. Sociedade Brasileira da Ciência em Animais de Laboratório. Disponível em http://www.cobea.org.br/site/capa. Acessado em 18/11/2016.

SIMS, R. R. The Institutionalization of Organizational Ethics. Journal of Business Ethics, v. 10, n. 7, p. 493-506, 1991.

SOARES, L. Q. Assédio moral no trabalho e interações socioprofissionais: "ou você interage do jeito deles ou vai ser humilhado até não agüentar mais". Dissertação (Mestrado em Psicologia), Universidade de Brasília, Brasília. 2006.

TEIXEIRA, M. O. Plataformas tecnológicas e as práticas de pesquisa em biomedicina observações preliminares sobre o uso de dispositivos globais e instituições locais. Sociologias, v. 14, n. 29, p. 312-336, 2012.

VAN ZUTPHEN, L. F. M. Use of animals in research: a science - society controversy? The European Perspective, Altex, v. 19, n. 3, p. 140-144, 2002.

VIANA, I. D. Mapeamento de processos geradores de resíduos em um biotério na perspectiva de avaliação de ciclo de vida. Dissertação (Mestrado em Tecnologia). Centro Federal de Educação Tecnológica Celso Suckow da Fonseca, 2011.

VIECILI, J.; MEDEIROS, J. G. A coerção e suas implicações na relação professor-aluno. PsicoUSF, v. 7, n. 2, p. 229-238, 2002.

WASSERMAN, S.; FAUST, K. Social Network Analysis: Method and Application. Cambridge, UK: Cambridge University Press, 1994.

WEBER, G. M. Identifying translational science within the triangle of biomedicine. Journal of Translational Medicine, v. 11, n. 126, p. 1-10, 2013.

WEBER, M. A Ética Protestante e o "Espírito" do Capitalismo. São Paulo: Companhia das Letras, 2004. 